Азиатско-Тихоокеанский регион: экономика, политика, право. 2021. Т. 24, № 4. С. 162-174. Pacific Rim: Economics, Politics, Law. 2021. V. 24, No 4. P. 162-174.

\title{
ПРАВО
}

Научная статья

УДК 343.851.5(094.2)

https://doi.org/10.24866/1813-3274/2021-4/162-174

\section{ИСПОЛНЕНИЕ НАКАЗАНИЯ В ВИДЕ ЛИШЕНИЯ СВОБОДЫ В ОТНОШЕНИИ НЕСОВЕРШЕННОЛЕТНИХ ОСУЖДЁННЫХ: МЕЖДУНАРОДНО-ПРАВОВОЙ АСПЕКТ}

\author{
Константин Викторович Каретников \\ Кузбасский институт ФСИН России, г. Новокузнецк, Россия; г. Новокузнецк, \\ проспект Октябрьский, 49; kostya_385@mail.ru
}

Аннотация. В статье рассматриваются отдельные положения норм международного права, касающиеся ключевых вопросов исполнения и отбывания наказания в виде лишения свободы осуждёнными несовершеннолетними в воспитательных колониях Федеральной службы исполнения наказаний России. Даётся характеристика действующих в настоящее время в пенитенциарной сфере международных правовых актов. Преследуется целью возможная имплементация международных норм в российскую правовую систему. Приводятся доводы ценности рассмотрения положений международных актов в отношении несовершеннолетних преступников, лишенных свободы. Производится группировка международных актов по различным основаниям. Отмечаются существующие проблемы в работе воспитательных колоний на современном этапе развития пенитенциарных учреждений России. Делается заключение о целесообразности имплементации и упорядочивания отдельных положений международных норм в уголовно-исполнительном законодательстве России. Приоритетным направлением, в этой связи, следует отметить наличие в Концепции развития уголовно-исполнительной системы России до 2030 г. положений относительно развития международного сотрудничества, использования опыта работы в пенитенциарной сфере зарубежных стран в деятельности уголовноисполнительной системы России.

(C) Каретников К. В., 2021 
Ключевые слова: несовершеннолетние, международные акты, осуждённые, наказание, исправительные учреждения, преступник, уголовно-исполнительная система, правонарушения, преступность, пенитенциарная система, воспитательные колонии, преступная деятельность, исполнение наказаний, правовые нормы, условия содержания, несовершеннолетний преступник, исправительное воздействие, система исполнения наказаний, профилактика, лишение свободы, места содержания, противоправная деятельность.

Для циитирования: Каретников К. В. Исполнение наказания в виде лишения свободы в отношении несовершеннолетних осуждённых: международно-правовой аспект // Азиатско-Тихоокеанский регион: экономика, политика, право. 2021. Т. 24, № 4. С. 162-174. https://doi.org/10.24866/1813-3274/2021-4/162-174.

\section{LAW}

Original article

\section{EXECUTION OF PUNISHMENT IN THE FORM OF IMPRISONMENT IN RELATION TO JUVENILE CONVICTS: INTERNATIONAL LEGAL ASPECT}

\section{Konstantin V. Karetnikov}

Kuzbass Institute of the Federal Penitentiary Service of Russia, Novokuznetsk, Russia; Novokuznetsk, 49 Oktyabrsky avenue; kostya_385@mail.ru

Abstract. The article examines certain provisions of the norms of international law concerning the key issues of the execution and serving of sentences in the form of imprisonment by convicted minors in educational colonies of the Federal Penitentiary Service of Russia. The characteristics of the international legal acts currently in force in the penitentiary sphere are given. The goal involves possible implementation of international norms into the Russian legal system. Arguments are given for the value of considering the provisions of international instruments in relation to juvenile criminals deprived of their liberty. The grouping of international acts is carried out on various grounds. The existing problems in the work of educational colonies at the present stage of development of penitentiary institutions in Russia are noted. A conclusion is made on the expediency of the implementation and ordering of certain provisions of international norms in the criminalexecutive legislation of Russia. A priority area, in this regard, should involve including the provisions on the development of international cooperation into the Concept for the Development of the Penitentiary System of Russia until 2030, and using the foreign penitentiary experience in the work of the penitentiary system of Russia. 
Keywords: minors, international acts, convicts, punishment, correctional institutions, criminal, penal system, offenses, crime, penitentiary system, educational colonies, criminal activity, execution of sentences, legal norms, conditions of detention, juvenile offender, corrective action, system of execution of sentences , prevention, imprisonment, places of detention, illegal activities.

For citing: Karetnikov K.V. Execution of Punishment in the form of imprisonment in relation to juvenile convicts: the international legal aspect // Pacific RIM: Economics, Politics, Law. 2021. V. 24, No 4. P. 162-174. https://doi.org/10.24866/1813-3274/2021-4/162-174.

Процесс реформирования уголовно-исполнительной системы (далее - УИС) России (далее - РФ) в настоящее время не завершён. Анализируя результаты реформирования УИС в период с 2010 г. по 2020 г., необходимо указать на проведение Президентом РФ, Правительством РФ, Федеральным собранием РФ, Министерством юстиции РФ и Федеральной службой исполнения наказаний России планомерной работы по созданию нормативных правовых актов, урегулировавших отдельные вопросы исполнения и отбывания уголовных наказаний и совершенствовавших направление соблюдения прав и свобод осуждённых, условия их содержания; по оптимизации исправительных учреждений и применению альтернативных лишению свободы уголовных наказаний к преступникам. Положения международных актов, касающиеся пенитенциарной сферы, безусловно, учитываются указанными субъектами при выработке и реализации уголовно-исполнительной политики государства. Сказанное отчасти подтверждают итоги деятельности УИС России за последнее десятилетие. Однако, несмотря на принимаемые меры, отдельные требования международных актов, по регулированию пенитенциарных правоотношений, не получили должного внимания и, как следствие, нормативного закрепления в уголовно-исполнительном законодательстве РФ. Этот факт подтверждает необходимость дальнейшего изучения, исследования, апробирования и имплементации в российскую правовую систему международных стандартов обращения с лицами, находящимися в местах лишения свободы.

Уголовно-исполнительное законодательство РФ, в соответствии с положениями основного закона страны, закрепляет главенствующее положение международных норм, поэтому если международным договором РФ установлены иные правила исполнения наказаний и обращения с осуждёнными, чем предусмотренные уголовно-исполнительным законодательством РФ, то применяются правила международного договора, о чём свидетельствует содержание статьи 3 Уголовно-исполнительного кодекса РФ (далее - УИК РФ). При этом, если положения норм международного права войдут (возможно, немного видоизменившись) в содержание УИК РФ, то это будет способствовать более качественному исполнению наказаний, правовой интеграции и, вероятно, скажется на уровне правонарушений (в том числе и 
групповых) в воспитательных колониях (далее - ВК), что в последнее время приобретает особую значимость.

В настоящее время ни одним государством не выработано «универсальной» системы профилактики правонарушений, которая могла бы способствовать уменьшению уровня преступных проявлений граждан как в местах лишения свободы, так и за её пределами. Именно поэтому важность приобретает международный опыт. Только в условиях консолидации общих усилий в борьбе с преступностью возможно добиться желаемого результата.

В научных кругах активно исследуется противоправная деятельность осуждённых, достигших совершеннолетия. Однако подростковая и детская преступность должного внимания не получает. Сложность представляет, в данном случае, антиобщественная и противоправная деятельность несовершеннолетних граждан, которые совершают преступления, находясь в возрасте, когда привлечение к уголовной ответственности является невозможным. Этот факт требует применять к ним меры воспитательного воздействия, однако во внимание не принимается то обстоятельство, что несовершеннолетние, ввиду присущей им эмоциональной нестабильности и незрелости, в данный период активно набираются криминального опыта. Отчасти это находит отражение в положениях международных стандартов обращения с лицами, преступившими закон.

Проблема динамики преступлений, которые совершаются именно несовершеннолетними, в последнее время вызывает у практических работников и в научных кругах всё большую тревогу и озабоченность [1, с. 7-10; 2, с. 17-19]. По данным МВД РФ, ежегодно несовершеннолетними или при их соучастии, вне мест лишения свободы, совершается порядка 34 тыс. противоправных действий. Особое внимание привлекают имеющиеся случаи вовлечения несовершеннолетних в деятельность организованных групп либо преступных сообществ различного толка. Именно поэтому в настоящее время преступность несовершеннолетних в России выступает комплексной проблемой в обществе, обусловливающей необходимость строгого контроля и пристального внимания со стороны общественности и различных государственных органов и структур [3, с. 12-14].

Современные веяния общественного развития говорят о том, что правовой статус несовершеннолетнего лица, гарантии его основных прав и свобод, в том числе в процессе содержания под стражей и в местах лишения свободы, должны соответствовать принципам и нормам Конституции РФ, общепризнанным принципам и нормам международного права, международным договорам РФ [4, с. 522-525]. Этот факт положительным образом отражается на количестве противоправных действий, совершённых несовершеннолетними, обусловливая достижение в отношении них целей уголовно-исполнительного законодательства, среди которых главенствующее положение занимают исправление и предупреждение совершения новых преступных посяга- 
тельств. В этом и прослеживается влияние международных актов в сфере уголовноисполнительных правоотношений на пенитенциарную систему России. Для более явного понимания рассматриваемого явления охарактеризуем отдельные положения международных стандартов, нашедших отражение в российской правовой системе.

Так, к числу международных актов, регламентирующих исполнение наказания в отношении несовершеннолетних осуждённых и обращения с ними, следует отнести:

Минимальные стандартные правила обращения с заключёнными (далее Минимальные правила) [5]. Некоторые положения п. 8 Минимальных правил нашли отражение в отдельном содержании несовершеннолетних от взрослых осуждённых; п.п. 9-14 - в вопросах материально-бытового и хозяйственного обеспечения ВК. Однако, как видится, с целью реализации п.п. 15-16 Минимальных правил необходимо более подробно регламентировать, в частности, вопросы личной гигиены несовершеннолетних осужденных, установив, как это указано в ПВР ИУ № 295, максимально допустимую длину волос на голове и лице. Этот факт подтверждается установленной процедурой эффективного выполнения Минимальных правил, согласно которой все государства должны принять указанные правила и воплотить их в национальном законодательстве;

Европейские Пенитенциарные правила [6]. Анализируя данный документ, приходим к выводу, что он, фактически, является моделью правил внутреннего распорядка пенитенциарного учреждения. В нём последовательно изложена информация (по главам), касающаяся основных направлений, регулируемых администрацией учреждения с момента прибытия осуждённого и до его освобождения. К примеру, п. 11.4 отражает информацию о необходимости содержания несовершеннолетних в условиях изоляции от вредных (негативных) влияний со стороны криминально заражённых лиц. В ВК не всегда возможно реализовать такое требование, учитывая тот факт, что в учреждении могут отбывать наказание осуждённые при рецидиве преступлений, а также большая доля несовершеннолетних тяготеет к нормам и правилам криминальной субкультуры. Главой 3 Пенитенциарных правил предусмотрены требования к персоналу учреждений УИС, интересными представляются данные об обязанности поддерживать и совершенствовать знания и профессиональную подготовку в условиях учреждений, а также получать большой опыт и подготовку для улучшения профессиональных качеств. Применительно к ВК такие требования имеют первоочередное значение, так как наличие квалифицированных сотрудников, способных работать с категорией несовершеннолетних, позволит в дальнейшем избежать рецидива преступности (в т.ч. пенитенциарного);

Минимальные стандартные правила отправления правосудия в отношении несовершеннолетних (Пекинские правила) [7]. Как справедливо отмечено в п. 1.4, вопросы правосудия в отношении несовершеннолетних должны стать составной частью направления национального развития государства. Помещение несовершеннолетнего в места лишения свободы, в соответствии с требованиями Пекинских 
правил, допускается в крайнем случае, при этом срок должен быть минимальным вне зависимости от совершённого преступного деяния. Этими положениями в противоправных целях пользуются взрослые преступники, вовлекая несовершеннолетних в совершение преступлений. Администрация ВК, в соответствии с п. 26.6 Пекинских правил, должна предпринять меры, направленные на избежание отрицательного влияния взрослых правонарушителей в условиях ИУ. Однако в условиях российской пенитенциарной системы имеются такие места, где возможен свободный контакт несовершеннолетних и взрослых осужденных - лечебно-профилактические учреждения, где по медицинским показаниям осужденные содержатся вне зависимости от вида ИУ, из которого они прибыли;

Руководящие принципы ООН по предупреждению преступности среди несовершеннолетних (Эр-Риядские руководящие принципы) [8]. В направлении профилактики преступности несовершеннолетних данный документ занимает ведущую позицию. В нём отмечается ведущая позиция профилактики преступности несовершеннолетних в рамках предупреждения преступности в обществе, а также возможность воспитания несовершеннолетних в духе гуманистических взглядов на общественные отношения, что позволит избежать совершения преступлений. Справедливо отмечено, что эффективной профилактика в среде несовершеннолетних будет только при усилии всего общества, а не отдельных его субъектов. При этом субъекты профилактики, как свидетельствует гл. 3 руководящих принципов, на всех её уровнях должны быть квалифицированными специалистами. Глава 7 подтверждает изложенную выше информацию относительно значимости активизации на международном уровне обмена данными, опытом и знаниями, полученными при реализации мероприятий, связанных с профилактической деятельностью преступных проявлений несовершеннолетних;

Руководящие принципы в отношении действий в интересах детей в системе уголовного правосудия [9]. Особое внимание в документе уделяется вопросам принятия в каждой стране процессуальных норм по делам несовершеннолетних, анализа и обзора качества применяемых норм в отношении несовершеннолетних, создания судов по делам несовершеннолетних. Поднятые вопросы являются достаточно спорными в условиях отечественной правовой системы;

Руководящие принципы, касающиеся правосудия в вопросах, связанных с участием детей, являющихся жертвами и свидетелями преступлений [10]. Данный международный акт освещает основные направления виктимизации преступности несовершеннолетних, так как они могут выступать не только субъектами совершения преступления, но и объектом преступного посягательства взрослого, несовершеннолетнего или группы таких лиц, что наиболее явно для ВК. Глава 12 регламентирует вопросы обеспечения безопасности несовершеннолетних, являющихся объектами преступных посягательств. Особый статус несовершеннолетних, а также особо уязвимое, с точки зрения виктимизации, положение даёт им право, на основании гл. 14, на применение специальных профилактических мер; 
Правила Организации Объединённых Наций, касающиеся защиты несовершеннолетних, лишенных свободы [11]. Этот международный акт отчасти повторяет положения Пекинских правил, но имеет и свои особенности. Так, п. 29 предусматривает возможность участия несовершеннолетних осуждённых совместно с характеризующимися положительно взрослыми осуждёнными в специальных программах, оказывающих исправительное воздействие на них. В качестве своеобразного передового опыта стоит указать положения п. 30, касающиеся создания открытых исправительных учреждений для несовершеннолетних (меры безопасности отсутствуют или ограничены), которые должны быть децентрализованы. Для оказания качественного и адресного исправительного воздействия количество содержащихся лиц должно быть минимальным, а само учреждение небольших размеров. К числу имплементированных положений следует отнести п. п. 63-65, согласно которым применение физической силы и средств сдерживания к несовершеннолетним разрешается в исключительных случаях, а вот применение и ношение на территории ВК оружия запрещается;

Типовые стратегии и практические меры Организации Объединенных Наций по ликвидации насилия в отношении детей в рамках предупреждения преступности и уголовного правосудия [12]. Положения указанного документа свидетельствуют о конкретных направлениях, в которых должно следовать мировое сообщество, предупреждение виктимизации детей должно признаваться приоритетной задачей в области предупреждения преступности; насилие несовершеннолетних над несовершеннолетними должно устраняться особыми мерами профилактики. Выработанные путём консолидации общих усилий различных стран направления профилактики преступности должны найти безоговорочное отражение в национальном законодательстве России по вопросам основ профилактики противоправного поведения несовершеннолетних.

Таким образом, вышеуказанные нормы являются основополагающими по отношению к несовершеннолетним, исполнение наказания в отношении которых закрепляет УИК РФ. Соблюдение указанных положений является обязанностью государства.

Вероятнее всего, предшествующая гуманизация в области уголовной и уголовно-исполнительной политики, а также положения норм международных актов обусловила указание в части 4 введённой с 04.07.2020 г. статьи 67.1 Конституции РФ информации о том, что «дети являются важнейшим приоритетом государственной политики России». Исходя из этого, государство взяло обязательство по созданию условий, направленных на всестороннее нравственное, духовное, интеллектуальное и физическое развитие детей, ставит целью воспитание в детях патриотизма, гражданственности и уважения к старшим.

Акцентируя внимание на деятельности УИС, отметим, что позитивное влияние на реформирование пенитенциарной системы России оказывают международные стандарты. Непосредственное отражение положений отдельных международных актов прослеживалось в Концепции развития УИС до 2020 г., свою актуаль- 
ность они приобрели в последующем совершенствовании деятельности пенитенциарной системы вплоть до 2030 г.

Практика показывает, что особенности несовершеннолетнего возраста, с одной стороны, осложняют работу с осуждёнными, так как диктуют персоналу ВК требования по учёту характерных особенностей личности несовершеннолетних в данном возрасте [13, с. 20-22]. Однако, с другой стороны, динамика развития личности несовершеннолетнего позволяет говорить об успешности целенаправленной педагогической работы квалифицированного в области подростковой педагогики и психологии персонала.

Так, к примеру, Правила ООН, касающиеся защиты несовершеннолетних, лишённых свободы, устанавливают, что основным критерием разделения несовершеннолетних на различные категории должно быть обеспечение таких условий, которые в особенности отвечали бы потребностям осужденных и обеспечивали бы защиту их физической, моральной, психической целостности. Вышеуказанное требование содержится, соответственно, и в уголовно-исполнительном законодательстве России. К сожалению, планы создания воспитательных центров, согласно Концепции развития УИС до 2020 г., реализованы не были. При этом, одним из позитивных аспектов реформирования УИС до 2020 г. стала оптимизация пенитенциарных учреждений, находящаяся в непосредственной зависимости от количества осуждённых и содержащихся под стражей. Так, за период с 2010 г. по 2020 г. количество ВК сократилось на 44 (с 62 до 18 учреждений соответственно), а количество осуждённых - на 3351 (с 4362 до 1017 человек соответственно).

Согласно требованию международных документов, пенитенциарные учреждения для несовершеннолетних осуждённых должны отвечать всем современным требованиям, чтобы наставить их на путь правопослушного поведения, привить любовь к трудовой деятельности и получению образования, саморазвитию, с целью дальнейшего их отказа от противоправной деятельности. Сегодня стоит по-иному взглянуть на места содержания и отбывания наказания несовершеннолетних преступников, наладив работу по их реорганизации и совершенствованию.

Полагаем, что в основу построения современной модели пенитенциарного учреждения, предназначенного для несовершеннолетних правонарушителей, следует включить некоторые принципы, содержащиеся в международных стандартах, как:

во-первых, раздельное содержание осуждённых с учётом тяжести совершённых ими противоправных деяний, уровня их общественной опасности;

во-вторых, комплексный подход к организации и осуществлению с осуждёнными планомерной, качественной и адресной социальной, психологической и воспитательной работы;

в-третьих, содержание осуждённых на протяжении всего периода отбывания наказания в одном исправительном учреждении, вне зависимости от возрастных критериев правонарушителя, с целью оказания непрерывного исправительного воздействия; 
в-четвёртых, действие «социального лифта» в процессе исправления несовершеннолетних осуждённых [14, с. 10-12; 15, с. 58-61].

Реализация указанных принципов позволит оказывать качественный воспитательный эффект в рамках общей превентивной функции УИС и в процессе исполнения наказания.

Федеральный закон РФ № 124 «Об основных гарантиях прав ребёнка» говорит о том, что к числу детей, находящихся в трудной жизненной ситуации, относятся несовершеннолетние, отбывающие наказание в ВК. Этот факт обязывает администрацию учреждения применять в отношении несовершеннолетних такие формы профилактики, как социальная адаптация и реабилитация, что способствует приобретению новых и восстановлению утраченных социальных связей и функций. Таким образом, подтверждается наличие положений норм международных стандартов в системе российского законодательства.

В числе основных проблем, которые необходимо решать и в рамках ВК, можно выделить: распространённость жестокого обращения с детьми и насилия в их отношении (как со стороны сотрудников учреждений, к примеру, при применении физической силы и специальных средств, так и со стороны сверстников осуждённых), низкая эффективность профилактической работы (подтверждается наличием устойчивого количества совершаемых ежегодно правонарушений и нарушений установленного порядка отбывания наказания), социальная исключённость уязвимых категорий детей (согласно действующему законодательству, лица несовершеннолетнего возраста, находящиеся в местах лишения свободы, относятся к категории «находящихся в трудной жизненной ситуации», что увеличивает уровень их незащищённости), отсутствие механизмов обеспечения участия детей в общественной жизни (достаточно сложно реализуемое направление ввиду изоляции несовершеннолетних в ВК, однако имеется выход посредством привлечения к участию в мероприятиях на территории исправительного учреждения), всё это должно решаться на протяжении всей жизни ребёнка, начиная с семьи и заканчивая школой, включая и воспитательные колонии, в том случае, если ребёнок попадает туда вследствие упущения в воспитании на предыдущих этапах [16, c. 32-34]. В данном случае стоит отметить и низкую, или даже не совсем эффективную, работу в сфере профилактики правонарушений субъектами превенции.

Таким образом, в условиях консолидации действий всего мирового сообщества предпринимается попытка организации исполнения наказаний в виде лишения свободы единообразно во всех государствах [4, с. 528-531]. Приоритетным направлением, в этой связи, необходимо считать наличие в Концепции развития УИС до 2030 г. положений, касающихся развития международного сотрудничества, использования опыта работы пенитенциарной сферы (в том числе предупреждения правонарушений) зарубежных стран в деятельности УИС России [17, с. 132-136]. 


\section{Список источников}

1. Прозументов, Л. М. Общесоциальные детерминанты преступности / Л. М. Прозументов, А. В. Шеслер // Всероссийский криминологический журнал. 2018. - Т. 12, № 1. - С. 5-14.

2. Савушкин, С. М. Международные стандарты в области дифференциации осужденных к лишению свободы // Научный вестник Омской академии МВД России. - 2017. - № 2 (65). - С. 15-20.

3. Беляева, Л.И. Исполнение наказания в виде лишения свободы в отношении несовершеннолетних: международные стандарты // Пенитенциарная наука. - 2008. - № 3. - С. 10-21.

4. Деревич, А. Р. Анализ регламентации международных стандартов, регулирующих правовое положение несовершеннолетних, осуждённых к лишению свободы // Бюллетень науки и практики. - 2018. - № 12. - С. 521-532.

5. Минимальные стандартные правила обращения с заключенными : резолюция Экономического и Социального Совета Организации Объединенных Наций от 30 августа 1955 г. - URL: https://www.un.org/ru/documents/decl_conv/ conventions/prison.shtml (дата обращения: 06.09.2021).

6. Европейские Пенитенциарные правила: рекомендация Комитета министров Совета Европы от 12 февраля 1987 г. № R(87)3 - URL: https://docs.cntd.ru/document/901732870 (дата обращения: 06.09.2021).

7. Минимальные стандартные правила Организации Объединенных Наций, касающиеся отправления правосудия в отношении несовершеннолетних (Пекинские правила) : резолюция Генеральной Ассамблеи Организации Объединенных Наций от 29 ноября 1985 г. № 40/33. - URL: https://www.unodc.org/ documents/justice-and-prison-reform/R_ebook.pdf (дата обращения: 06.09.2021).

8. Руководящие принципы Организации Объединенных Наций для предупреждения преступности среди несовершеннолетних (Руководящие принципы, принятые в Эр-Рияде) : резолюция Генеральной Ассамблеи Организации Объединенных Наций от 14 декабря 1990 г. № 45/112. - URL: https://www.unodc.org/documents/justiceand-prison-reform/R_ebook.pdf (дата обращения: 06.09.2021).

9. Руководящие принципы в отношении действий в интересах детей в системе уголовного правосудия : резолюция Экономического и Социального Совета Организации Объединенных Наций от 21 июля 1997 г. № 1997/30. - URL: https://www.unodc.org/documents/justice-and-prison-reform/R_ebook.pdf (дата обращения: 06.09.2021).

10. Руководящие принципы, касающиеся правосудия в вопросах, связанных с участием детей-жертв и свидетелей преступлений : резолюция Экономического и Социального Совета Организации Объединенных Наций от 22 июля 2005 г. 
№ 2005/20. - URL: https://www.unodc.org/documents/justice-and-prison-reform/R_ebo ok.pdf (дата обращения: 06.09.2021).

11. Правила Организации Объединенных Наций, касающиеся защиты несовершеннолетних, лишенных свободы : резолюция Генеральной Ассамблеи Организации Объединенных Наций от 14 декабря 1990 г. № 45/113. - URL: https://www.unodc.org/documents/justice-and-prison-reform/R_ebook.pdf (дата обращения: 06.09.2021).

12. Типовые стратегии и практические меры Организации Объединенных Наций по ликвидации насилия в отношении детей в рамках предупреждения преступности и уголовного правосудия : резолюция Генеральной Ассамблеи Организации Объединенных Наций от 18 декабря 2014 г. № 69/194. - URL: https://www.unodc.org/documents/justice-and-prison-reform/R_ebook.pdf (дата обращения: 06.09.2021).

13. Иванова, Л. М. Международно-правовые основы ювенальной юстиции / Л. М. Иванова, А. В. Харитонова // ГлаголЂ правосудия. - 2019. - № 2. - С. 19-24.

14. Борченко, В.А. Общетеоретический анализ международно-правового регулирования в сфере обращения с осуждёнными в российской пенитенциарной системе / В. А. Борченко, Е. В. Глебова // Вестник Самарского юридического института. - 2020. - № 5 (41). - С. 9-12.

15. Садовникова, М. Н. Международные стандарты обращения с несовершеннолетними правонарушителями: некоторые терминологические проблемы, обзор основных нормативно-правовых актов // Сибирский юридический вестник. 2005. - № 4. - C. 55-61.

16. Прохорова, М. В. Отражение стимулирования позитивной активности несовершеннолетних, осуждённых к лишению свободы, в международных стандартах // Вестник Кузбасского института. - 2011. - № 1 (4). - С. 32-35.

17. Тепляшин, П. В. Концепция развития уголовно-исполнительной системы России в свете интерпретированных принципов европейской пенитенциарной практики // Вестник Санкт-Петербургского университета. Секция: право. - 2020. T. 11, № 1. - C. 129-139.

\section{Информация об авторе}

К. В. Каретников - преподаватель кафедры организации режима, охраны и конвоирования Кузбасского института Федеральной службы исполнения наказаний России; аспирант кафедры уголовного права и криминологии Юридического института Красноярского государственного аграрного университета. 


\section{References}

1. Prozumentov L. M., Shesler A. V. Obshchesotsial'nye determinanty prestupnosti [General social determinants of crime. Vserossiiskii kriminologicheskii zhurnal, 2018, vol. 12, no. 1, pp. 5-14.

2. Savushkin S. M. Mezhdunarodnye standarty v oblasti differentsiatsii osuzhdennykh $\mathrm{k}$ lisheniyu svobody [International standards in the field of differentiation of those sentenced to imprisonment]. Nauchnyi vestnik Omskoi akademii MVD Rossii, 2017, no. 2 (65), pp. 15-20.

3. Belyaeva L. I. Ispolnenie nakazaniya $\mathrm{v}$ vide lisheniya svobody $\mathrm{v}$ otnoshenii nesovershennoletnikh: mezhdunarodnye standarty [Execution of punishment in the form of imprisonment against minors: international standards]. Penitentsiarnaya nauka, 2008, no. 3, pp. 10-21.

4. Derevich A. R. Analiz reglamentatsii mezhdunarodnykh standartov, reguliruyushchikh pravovoe polozhenie nesovershennoletnikh, osuzhdennykh $\mathrm{k}$ lisheniyu svobody [Analysis of the regulation of international standards governing the legal status of minors sentenced to imprisonment]. Byulleten' nauki i praktiki, 2018, no. 12, pp. 521-532.

5. Minimum Standard Rules for the treatment of prisoners: Resolution of the Economic and Social Council of the United Nations of August 30,1955. Available at: https://www.un.org/ru/documents/decl_conv/conventions/prison.shtml (accessed 06 September 2021).

6. European Penitentiary Rules: recommendation of the Committee of Ministers of the Council of Europe of February 12, 1987 No. R(87)3. Available at: https://docs.cntd.ru/document/901732870 (accessed 06 September 2021).

7. United Nations Standard Minimum Rules for the administration of juvenile justice (Beijing Rules): United Nations General Assembly Resolution No. 40/33 of November 29, 1985. Available at: https://www.unodc.org/documents/justice-and-prisonreform/R_ebook.pdf (accessed 06 February 2021).

8. United Nations Guidelines for the prevention of juvenile delinquency (Guidelines adopted in Riyadh): Resolution of the United Nations General Assembly of December 14, 1990 No. 45/112. - Access mode: https://www.unodc.org/documents/justice-andprison-reform/R_ebook.pdf (date accessed: 09/06/2021).

9. Guidelines for Action for children in the criminal justice system: Resolution of the United Nations Economic and Social Council Resolution No. 1997/30 of July 21, 1997. Available at: https://www.unodc.org/documents/justice-and-prisonreform/R_ebook.pdf (accessed 06 February 2021).

10. Guidelines on justice in matters related to the participation of child victims and witnesses of crime : Resolution of the United Nations Economic and Social Council of July 22, 2005 No. 2005/20. Available at: https://docs.cntd.ru/document/9019668 87? section=text (accessed 06 February 2021). 
11. Rules of the United Nations concerning the protection of minors deprived of their liberty: Resolution of the General Assembly of the United Nations of December 14,1990 No. 45/113. Available at: https://www.unodc.org/documents/justice-and-prisonreform/R_ebook.pdf (accessed 06 February 2021).

12. United Nations Model Strategies and Practical Measures to Eliminate Violence against Children in Crime Prevention and Criminal Justice: United Nations General Assembly Resolution No. 69/194 of December 18,2014. Available at: https://www.unodc.org/documents/justice-and-prison-reform/R_ebook.pdf (accessed 06 February 2021).

13. Ivanova L. M., Kharitonova A. V. Mezhdunarodno-pravovye osnovy yuvenal'noi yustitsii [International legal foundations of juvenile justice]. Glagol"" pravosudiya, 2019, no. 2, pp. 19-24.

14. Borchenko V. A., Glebova E. V. Obshcheteoreticheskii analiz mezhdunarodnopravovogo regulirovaniya $\mathrm{v}$ sfere obrashcheniya s osuzhdennymi $\mathrm{v}$ rossiiskoi penitentsiarnoi sisteme [General theoretical analysis of international legal regulation in the field of treatment of convicts in the Russian penitentiary system]. Vestnik Samarskogo yuridicheskogo instituta, 2020, no. 5 (41), pp. 9-12.

15. Sadovnikova M. N. Mezhdunarodnye standarty obrashcheniya s nesovershennoletnimi pravonarushitelyami: nekotorye terminologicheskie problemy, obzor osnovnykh normativno-pravovykh aktov [International standards for the treatment of juvenile offenders: some terminological problems, an overview of the main regulatory legal acts]. Sibirskii yuridicheskii vestnik, 2005, no. 4, pp. 55-61.

16. Prokhorova M. V. Otrazhenie stimulirovaniya pozitivnoi aktivnosti nesovershennoletnikh, osuzhdennykh $\mathrm{k}$ lisheniyu svobody, $\mathrm{v}$ mezhdunarodnykh standartakh [Reflection of stimulating the positive activity of minors sentenced to imprisonment in international standards]. Vestnik Kuzbasskogo instituta, 2011, no. 1 (4), pp. 32-35.

17. Teplyashin P. V. Kontseptsiya razvitiya ugolovno-ispolnitel'noi sistemy Rossii $\mathrm{v}$ svete interpretirovannykh printsipov evropeiskoi penitentsiarnoi praktiki [The concept of development of the penal system in Russia in the light of the interpreted principles of European penitentiary practice]. Vestnik Sankt-Peterburgskogo universiteta. Sektsiya: parvo, 2020, vol. 11, no. 1, pp. 129-139.

\section{Information about the author}

K. V. Karetnikov - Lecturer of the Department of Organization of Regime, Security and Escort of the Kuzbass Institute of the Federal Penitentiary Service of Russia; Postgraduate student of the Department of Criminal Law and Criminology of the Law Institute of the Krasnoyarsk State Agrarian University. 